\title{
Controlled Crystallization of the Amorphous Phase in Silicon Nitride Ceramics
}

\author{
DAWN A. BONNELL * \\ Department of Ceramic Sciences, IBM Thomas Watson Research Center, Yorktown Heights, New York 10598 \\ TSENG-YING TIEN* \\ Department of Materials Science and Engineering, The University of Michigan, Ann Arbor, Michigan 48109
}

MANFRED RUHLE *

Department of Materials Science, University of California, Santa Barbara, California 93106

The controlled crystallization of amorphous second phases in SiAION is demonstrated in two systems. In a magnesiacontaining SiAION, cordierite crystallized on annealing after hot-pressing. Similarly, garnet crystallized in yttria-containing SiAION. The resulting microstructures are characterized by TEM and qualitatively related to changes on roomtemperature toughness and high-temperature deformation.

\section{Introduction}

$\mathbf{S}_{\text {oped }}$ LICON NITRIDE is among the materials currently being developed for high-temperature structural applications. ${ }^{\text {' While the }}$ covalent nature of the silicon nitrogen bond should provide attractive material properties such as chemical inertness, high hardness, and strength, it also prohibits densification of powder compacts without the aid of oxide sintering agents. At sintering temperatures the oxide mixtures form a eutectic liquid with silicon nitride providing the medium for liquid-phase sintering and solutionprecipitation processes. ${ }^{2}$ During sintering, crystalline silicon nitride in the $\alpha$ modification transforms to the $\beta$ modification. ${ }^{3}$ If aluminum and oxygen are present in the liquid phase, some amount will be incorporated into the $\beta$ grains during the transformation forming a solid solution of silicon nitride according to the formula $\mathrm{Si}_{6-x} \mathrm{Al}_{x} \mathrm{O}_{x} \mathrm{~N}_{8-x}$, which is referred to as SiAlON. ${ }^{4}$ On cooling, the liquid becomes a glassy grain-boundary phase which degrades mechanical properties, particularly at elevated temperatures. ${ }^{5}$

Three approaches for reducing the glass-phase content which have been considered are (1) transient liquid-phase sintering where constituents of the glass phase are absorbed into the silicon nitride grains by solid solution, ${ }^{6}(2)$ the development of densification processes such as gas pressure sintering which require less liquid phase, ${ }^{7.8}$ and (3) postsintering treatments to alter the glass composition. 9.10

A fourth approach for reducing glass content is to crystallize compounds from the glass in postsintering annealing treatments. Rae et al. " characterized several yttrium oxynitrides as reaction products from grain-boundary glass devitrification. Tsuge et al. ${ }^{12}$ demonstrated that the high-temperature strength of silicon nitrides improved when $\mathrm{Si}_{3} \mathrm{~N}_{4} \mathrm{Y}_{2} \mathrm{O}_{3}$ is crystallized. In other systems, Wild

Received March 20, 1986; revised copy received October 14, 1986; approved December 30, 1986

Supported by the U.S. Department of Energy. Office of Basic Energy Sciences, Division of Materials Science, under Contract No. DE-FG02-84-ER45069 and the Max-Planck-Institut for Metallforschung.

* Member, the American Ceramic Society. et al. ${ }^{13}$ found some evidence for the presence of $\mathrm{MgSiO}_{3}$ (enstatite) in the grain-boundary phase of $\mathrm{Mg}$-containing silicon nitride. The most successful grain-boundary crystallization occurred in the yttrium SiAION system where Hohnke et al. ${ }^{14}$ and Lewis et al. ${ }^{15}$ showed that yttrium aluminum garnet could be crystallized. Lewis suggested that not only the reaction products but also the amount of residual glass can be controlled by altering the composition through AIN polytype additions. The reduction in glass-phase content accompanying the crystallization was associated with an improved creep resistance, but unfortunately, a strength and toughness reduction also occurred on grain-boundary glass crystallization. The causes of this strength and toughness reduction are not understood. One possibility is that high residual stresses are developed due to thermal expansion mismatch between the silicon nitride and garnet. Cracks could develop in regions of concentrated tensile stress, causing the observed decreases in strength and toughness.

The motivation of the work was to develop a method for controlling grain-boundary-phase crystallization and use it to examine the role of crystallization on mechanical properties. Maximum crystallization (and highest reduction of glass-phase content) will occur when the bulk composition is on a plane of silicon nitride subsolidus compatibility with a compound which contains an extensive glass-forming region at higher temperatures. Crystallization products of the glass phase are expected to depend on glass composition after sintering and, when appropriate phase relations are known, it should be possible to control processing such that one oxide and secondary silicon nitride are the only crystallization products. Many combinations of oxide or oxynitride compounds with silicon nitride or SiAlONs can be envisioned based on known phase relations. Some oxynitride compounds have been shown to exhibit deleterious oxidation behavior in silicon nitride and these must be avoided. ${ }^{16}$ This paper describes a study in which controlled grain-boundary glass-phase crystallization is demonstrated in two SiAION systems, one containing yttria and alumina additives and one containing magnesia, silica, and alumina additives. Complete grain-boundary-phase crystallization is attempted through careful composition control including compensation for impurities. The resulting differences in grain-boundary morphology are illustrated and differences in toughness and high-temperature deformation are compared.

\section{Experimental Procedure}

\section{(1) Specimen Preparation}

Two series of SiAION compositions were investigated, one in which the ratios of oxides correspond to yttrium aluminum garnet 
$\left(\mathrm{Y}_{3} \mathrm{Al}_{5} \mathrm{O}_{12}\right)$ and one in which they correspond to cordierite $\left(\mathrm{Mg}_{2} \mathrm{Al}_{4} \mathrm{Si}_{5} \mathrm{O}_{14}\right)$. These experiments emphasize the cordierite SiAlON characterization which can then be compared to previous work in the garnet SiAlONs. ${ }^{14.15}$ As listed in Tables I and II, for each series the amount of $\mathrm{Al}$ substitution in the SiAlON was varied as the volume fraction of second phase remained constant, then the volume fraction of second phase was varied with a constant degree of $\mathrm{Al}$ solution. The bulk compositions were chosen to be on a plane of subsolidus ternary compatibility: silicon nitride- $\mathrm{Si}_{4} \mathrm{Al}_{2} \mathrm{O}_{2} \mathrm{~N}_{6}$ cordierite ${ }^{17}$ or silicon nitride- $\mathrm{Si}_{2} \mathrm{Al}_{4} \mathrm{O}_{4} \mathrm{~N}_{4}$-garnet. ${ }^{18}$ Composition control involved the compensation of oxygen impurity in the starting powders, impurity pickup from the milling media, and accounting for the $\mathrm{Al}$ and $\mathrm{O}$ that is expected to be incorporated into the silicon nitride grains. Accurate composition correction relies on a knowledge of phase relations for the full six-component systems, which fortunately, are available. ${ }^{14,19}$

Starting powders were $\mathrm{Si}_{3} \mathrm{~N}_{4}, \mathrm{Al}_{2} \mathrm{O}_{3}, \mathrm{MgCO}_{3}, \mathrm{AlN}$, and $\mathrm{Y}_{2} \mathrm{O}_{3}$ as given in Table $\mathrm{I}$. Powders were milled in polyethylene bottles under anhydrous ethanol for $5 \mathrm{~h}$ with alumina balls. (The material designation $\beta_{y}-Z$ represents a $\beta$-silicon nitride substituted to $y$ eq $\% \mathrm{Al}$ with $Z$ wt $\%$ additive. For example $\beta_{10^{-}} 10$ identifies a sample with $10 \mathrm{eq} \% \mathrm{Al}$ in the silicon nitride structure (corresponding to $x=0.77$ in the solution formula), with $10 \mathrm{wt} \%$ cordierite or garnet.) After drying, powders were compacted in BN-coated graphite dies, hot-pressed at $1700^{\circ} \mathrm{C}$ under $30-\mathrm{MPa}$ uniaxial compression for $2 \mathrm{~h}$ in a flowing nitrogen atmosphere. Based on previously determined kinetic data for the $\alpha$-to- $\beta$ transformation, hot-pressing conditions were chosen such that the $\alpha$-to- $\beta$ transformation was complete, thus maintaining desired composition in the glass phase (as discussed above, the transformation depletes the glass phase of $\mathrm{Al}$ and the original composition compensation assumed a completed transformation). It should be noted that composition deviations may result from vapor-phase reactions that occur during sintering. As phase relations for these systems are expressed as "behavior diagrams" which ignore the vapor phases, care must be taken to avoid furnace reactions or compensate for them. Weight losses were negligible for the samples investigated here, implying that closed-system reactions occurred requiring no vapor reaction compensation.

After hot-pressing, sample surfaces contaminated with carbon were removed by grinding. Three-centimeter-diameter disks were halved and annealed in a Pt wound vertical tube furnace in flowing nitrogen. Annealing times and temperatures are listed in Table II along with results of phase analysis as determined by X-ray diffractometry using $\mathrm{Cu} K \alpha$ radiation.

\section{(2) Transmission Electron Microscopy}

Disks $3 \mathrm{~mm}$ in diameter were prepared from the hot-pressed and annealed samples by conventional methods. The foils were mechanically ground to $100 \mu \mathrm{m}$, dimpled to $60 \mu \mathrm{m}$, and ion milled. A thin film of carbon was evaporated onto the foil to avoid charging while under the electron beam. A $200-\mathrm{kV}$ microscope with an $X$-ray energy dispersive spectroscopy (XEDS) system was used for TEM. To increase the reliability of X-ray energy dispersive spectroscopy analysis, transmission electron microscopy was performed primarily on $\beta_{10}-10$ samples because the SiAlON grains from these samples produced an Al signal large enough to reproducibly deconvolute from the background. Second-phase regions were large enough to analyze without phase overlap.

\section{(3) Mechanical Properties}

An indentation crack length method was used for toughness measurement. ${ }^{20}$ At least five indentations at each of three to four load levels were made with a diamond pyramid indenter for each sample. Samples were indented at room temperature in air with load varying from 30 to $70 \mathrm{~N}$. Measurement of the indentation and the cracks produced allowed calculation of the fracture toughness, according to

$$
K_{C}=\chi(E / H)^{1 / 2} P / c^{3 / 2}
$$

where $E$ is Young's modulus, $c$ is the measured crack length, $P$ is
Table I. Sample Compositions

\begin{tabular}{|c|c|c|c|c|c|c|}
\hline \multirow[b]{2}{*}{ Material } & \multicolumn{6}{|c|}{ Composition (wt \%) } \\
\hline & $\mathrm{Si}_{3} \mathrm{~N}_{4} *$ & $\mathrm{Al}_{2} \mathrm{O}_{3}{ }^{\top}$ & $\mathrm{AIN}^{\ddagger}$ & $\mathrm{SiO}_{2}^{\mathrm{s}}$ & $\mathrm{MgO}^{7}$ & $\mathrm{Y}_{2} \mathrm{O}_{3}{ }^{* *}$ \\
\hline$\beta_{5}-20$ & 75.53 & 7.60 & 4.12 & 10.27 & 2.76 & \\
\hline$\beta_{10}-10$ & 78.59 & 8.67 & 6.09 & 5.24 & 1.41 & \\
\hline$\beta_{30-10}$ & 57.20 & 24.77 & 11.50 & 5.12 & 1.38 & \\
\hline $\boldsymbol{\beta}_{10}-10$ & 78.87 & 9.53 & 6.10 & & & 5.85 \\
\hline
\end{tabular}

*H. Stark LC12, Hermann C. Stark, Inc., New York. ${ }^{\dagger}$ Alcoa A 16, Aluminum Company of America, Pittsburgh, PA. ${ }^{7}$ H. Stark. "Mallinckrodt Inc., St. Louis, MO (salicic acid calcined $\left.5 \mathrm{~h}, 1000^{\circ} \mathrm{C}\right)$. "Mallinckrodt, Inc. $\left(\mathrm{MgCO}_{3}\right.$ calcined $1 \mathrm{~h}$ $\left.1000^{\circ} \mathrm{C}\right)$. ${ }^{* *}$ Malycorporation 5600

Table II. Processing and Phase Analysis

\begin{tabular}{lccc}
\hline \multicolumn{1}{c}{ Sample } & \multicolumn{1}{c}{ Sintering } & Annealing & Phases* \\
\hline$\beta_{5}-20$ (cord) & $2 \mathrm{~h}, 1700^{\circ} \mathrm{C}$ & $0.5-191 \mathrm{~h}, 1000^{\circ} \mathrm{C}$ & $\beta, \mathrm{C}$ \\
& & $0.3-20 \mathrm{~h}, 1160^{\circ} \mathrm{C}$ & $\beta, \mathrm{C}$ \\
$\beta_{5}-10$ (cord) & $2 \mathrm{~h}, 1700^{\circ} \mathrm{C}$ & $0.5-120 \mathrm{~h}, 1000^{\circ} \mathrm{C}$ & $\beta, \mathrm{C}$ \\
$\beta_{5}-5$ (cord) & $2 \mathrm{~h}, 1700^{\circ} \mathrm{C}$ & $0.25-98 \mathrm{~h}, 1000^{\circ} \mathrm{C}$ & $\beta, \mathrm{C}$ \\
$\beta_{5}-20$ (garnet) & $2 \mathrm{~h}, 1700^{\circ} \mathrm{C}$ & $0.25-10 \mathrm{~h}, 1350^{\circ} \mathrm{C}$ & $\beta, \mathrm{G}, \mathrm{Y}$ \\
& $2 \mathrm{~h}, 1740^{\circ} \mathrm{C}$ & $0.5-50 \mathrm{~h}, 1250^{\circ} \mathrm{C}$ & $\beta, \mathrm{G}$ \\
& $2 \mathrm{~h}, 1740^{\circ} \mathrm{C}$ & $0.2-40 \mathrm{~h}, 1350^{\circ} \mathrm{C}$ & $\beta, \mathrm{G}$ \\
$\beta_{5}-10$ (garnet) & $2 \mathrm{~h}, 1740^{\circ} \mathrm{C}$ & $20 \mathrm{~h}, 1350^{\circ} \mathrm{C}$ & $\beta, \mathrm{G}$ \\
$\beta_{5}-5$ (garnet) & $2 \mathrm{~h}, 1740^{\circ} \mathrm{C}$ & $20 \mathrm{~h}, 1350^{\circ} \mathrm{C}$ & $\beta, \mathrm{G}$ \\
\hline
\end{tabular}

${ }^{*} \mathrm{G}=$ gantet, $\mathrm{C}=$ cordierite, $\mathrm{Y}=$ yttrium oxynitride

the peak contact load, $\chi$ is a constant depending on indenter geometry, and

$$
H=P / 2 a^{2}
$$

where $a$ is the impression semidiagonal. The term $P / c^{3 / 2}$ was found to be constant, indicating no variation of toughness with crack length. Cracks introduced by the indentation were much larger than the grain size (at least by a factor of 10) and were predominately intergranular in nature

Four-point-bend tests were carried out in a $\mathrm{SiC}$ test fixture that produced rolling point contacts on the tensile face and angular point contacts on the compressive face of the test bar. The fixture was installed in a box furnace, as described by Quinn ${ }^{21}$ and mounted on a universal testing machine. Test bars were cut with a diamond saw to rectangular dimensions of $0.085 \mathrm{in}$., $0.110 \mathrm{in}$., $1.347 \mathrm{in}$. The corners were chamfered to remove spurious flaws and the entire bar was polished to a 6- $\mu \mathrm{m}$ finish. To determine sample deflection, deflection arising from the compliance of the loading system was measured and subtracted from the total deflection. High-temperature tests were conducted at a constant crosshead displacement rate of $0.05 \mathrm{in} . / \mathrm{s}$.

\section{Results}

\section{(1) Composition Control}

After hot-pressing, samples from both the yttria and cordierite containing systems were composed of $\beta$-SiAlON and an amorphous second phase. The microstructure typical of the hot-pressed samples is shown in Fig. 1. The silicon nitride has undergone the $\alpha$-to- $\beta$ phase transition during hot-pressing which produced characteristically hexagonal $\beta$ grains containing 9 to $11 \mathrm{eq} \% \mathrm{Al}$ for the $\beta_{10}-10$ materials of both systems. This demonstrates the possibility of controlling the degree of solid solution in the final silicon nitride structure through the transformation and in the presence of a second phase. The additives formed a liquid coating two-grain junctions and the remaining liquid concentrated at three- and fourgrain junctions, as illustrated in the diffuse dark-field image (Fig. 1). Because of the relatively high volume fraction of glass phase (calculated at $12 \%$ in the cordierite SiAION and $7 \%$ in the garnet $\mathrm{SiAlON}$ ), many second-phase regions are not strictly fourgrain junctions. Such regions will be referred to as second-phase pockets. The composition of glass phase in the cordierite SiAlON, as determined by XEDS (normalized to $100 \%$ without oxygen and 


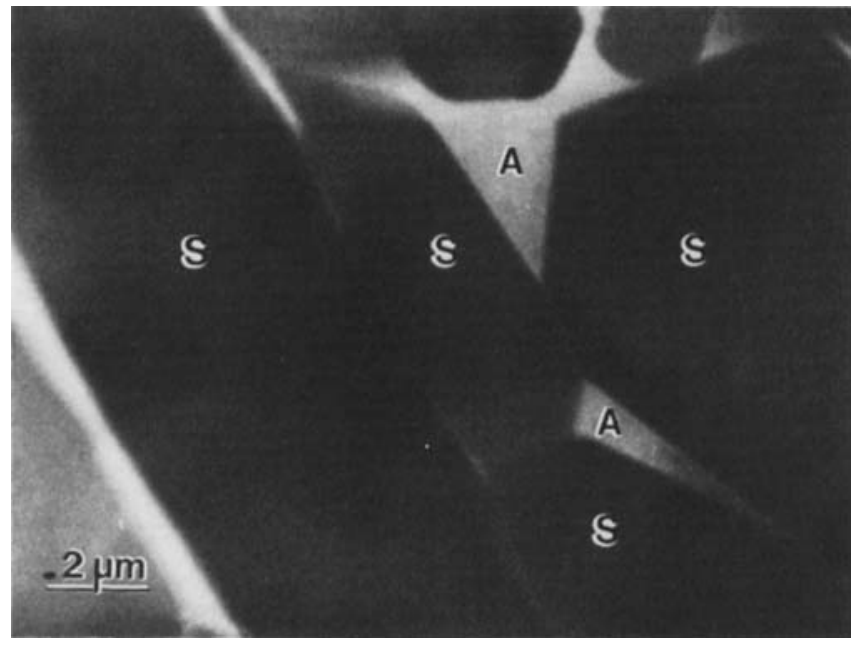

Fig. 1. Microstructure of hot-pressed samples is illustrated in this diffuse dark-field image of $\beta_{10}-10$ cordierite SiAION. SiAlON grains are labeled $S$, amorphous second phase is labeled $A$.

nitrogen), was $33.0 \mathrm{wt} \% \mathrm{Al}, 13.0 \mathrm{wt} \% \mathrm{Mg}, 54.0 \mathrm{wt} \% \mathrm{Si}$. Glass composition was homogeneous to within $\pm 3 \%$ in samples containing more than 5 vol\% glass. This composition is to be expected from the application of the lever to phase diagram and corresponds to cordierite which has dissolved some silicon nitride. Likewise the composition of the garnet SiAlON glass is $17.0 \mathrm{wt} \% \mathrm{Al}$, $55.0 \mathrm{wt} \% \mathrm{Y}, 28.0 \mathrm{wt} \% \mathrm{Si}$, which corresponds to silicon nitride dissolved in garnet. These compositions indicate that proper composition control has been maintained to this point in processing and maximum crystallization of the glass will be possible.

Oxide crystallization that occurred during annealing is shown in Fig. 2, where the vertical axis is a ratio of the average of two oxide peak intensities to the average of two silicon nitride peak intensities. Complete crystallization refers to samples annealed well past the time of maximum crystallization product, for the cordierite SiAlON annealed more than $90 \mathrm{~h}$ at $1000^{\circ} \mathrm{C}$ and the garnet SiAION annealed more than $40 \mathrm{~h}$ at $1250^{\circ} \mathrm{C}$. At complete crystallization a very fine film (on the order of 1 to $2 \mathrm{~nm}$ ) of amorphous phase is assumed to exist at two-grain junctions but is also assumed to be reduced to this limit which is predicted to be stable. ${ }^{22}$

\section{(2) Morphology}

Cordierite crystallized into a very fine-grained structure with a grain size much smaller than that of the silicon nitride. Figure 3 illustrates the discrete nature of the crystallites that have precipitated in a second-phase pocket. In the case of cordierite, with large lattice dimensions $(>1.7 \mathrm{~nm})$ and small grain size $(<0.1 \mu \mathrm{m})$, a series of images is necessary to distinguish discreteness of the structure. That these areas can be independently illuminated in dark field means that they are imaged with intensity from different diffraction patterns and are therefore different crystals. This confirms that the contrast variations seen in bright field are in fact produced by the polycrystalline nature of the grain-boundary cordierite and serves to characterize the grain size.

Dispersed in the cordierite are small faceted grains (Fig. 4) which exhibit contrast variations similar to SiAION and have an extremely high $\mathrm{Si}: \mathrm{Al}$ ratio. While it is beyond the spatial resolution of XEDS to accurately measure the composition of these grains, it is reasonable to conclude that they are silicon nitride grains which precipitated during annealing. The high Si content of these grains and the absence of additional phases in X-ray diffraction phase analysis support this assumption.

In contrast to the cordierite morphology, garnet has a largegrained structure with the grain size much larger than that of the silicon nitride. Figure 5 illustrates the morphology typical of garnet through bright-field-dark-field comparison. The garnet can be identified in the bright-field image because of its darker contrast, i.e., higher average atomic number. As the image in Fig. $5(B)$ was produced with a single spot from the garnet diffraction pattern, the illuminated areas of this image identify a singlecrystal orientation. Further, the continuous bend contours in the upper right section of the micrograph imply that this area is a single crystal. Note that the size of this garnet crystal is as large as or larger than the SiAlON crystals. The small-grained high-Si-content second phase was not observed in the garnet SiAlON; however, this is consistent with previous work ${ }^{17}$ showing that it precipitates instead on primary grains.

\section{(3) Mechanical Properties}

Figure 6 relates the room-temperature fracture toughness to composition and state of the second phase (crystalline or amorphous). A decrease in toughness with increasing glass content was seen in the hot-pressed samples of both systems. More dramatic differences are observed between the amorphous and crystallized samples. After cordierite crystallizes at the grain boundaries of SiAlON, the toughness increases, whereas the toughness decreases when the garnet crystallizes. Although distinguishable at low additive contents, the toughness differences become more pronounced as the amount of additive is increased. In addition to changes in room-temperature properties, differences in high-temperature properties were also observed. As an indication of hightemperature mechanical response, sample deflection at failure as a function of temperature is shown in Figs. $7(A)$ and $(B)$ for the crystallized and uncrystallized cordierite SiAION. Deflection of the crystallized samples is independent of temperature to $1200^{\circ} \mathrm{C}$; however, the uncrystallized samples undergo 3 times the deflection of the crystallized samples in these temperature ranges.
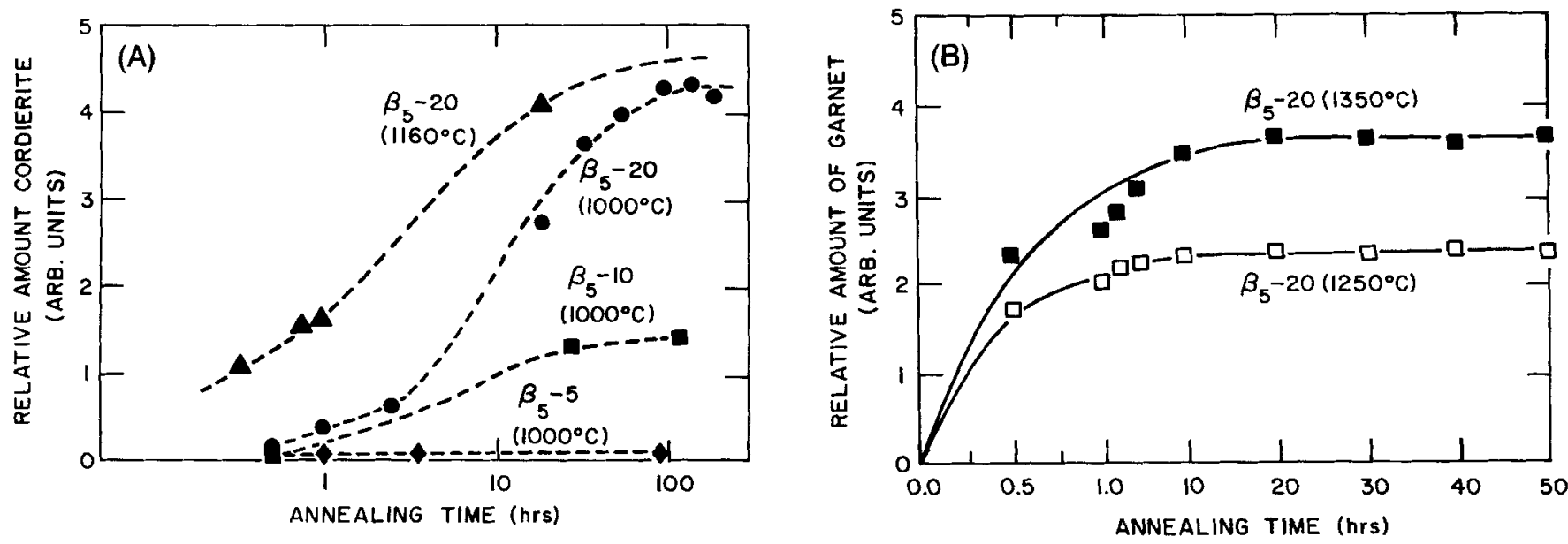

Fig. 2. Second-phase crystallization is shown as a function of time and temperature for both the cordierite and garnet SiAlON. 


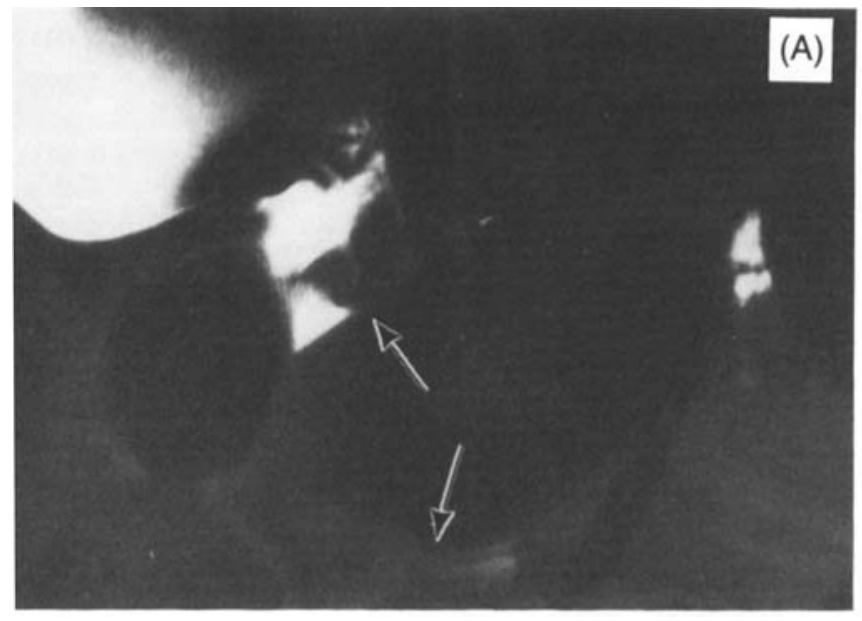

Fig. 3. A series of dark-field images characterizes the structure of the crystallized cordierite. Cordierite areas that can be shown independently in light contrast are separate crystals (i.e., grains). Arrows point out examples of such areas.

Improvements in the high-temperature deformation of material with the crystallized grain-boundary phase and therefore significantly reduced glass volume fraction (compare Figs. 1 and 4) are clearly demonstrated. This improvement with grain-boundaryphase crystallization is evident regardless of the volume fraction of second phase which can be seen by comparing Fig. $7(A)$ with Fig. $7(B)$. This can be compared with similar results reported for the crystallized garnet $\mathrm{SiAlON} .^{15}$

\section{Discussion}

During annealing, the oxide and silicon nitride are the only crystallization products, demonstrating composition control to the extent that grain-boundary crystallization products can now be predetermined (Table II). Had composition control not been strictly observed, the composition would be expected to shift to a region of quaternary compatibility and additional phases would crystallize from the glass. Specifically, the cordierite SiAION, forsterite, spinel, enstatite, or $\mathrm{O}^{\prime}$ oxynitride phase would be observed if the glass had lost nitrogen or magnesium and any one of the AlN polytypes could be observed if the glass had lost oxygen. ${ }^{19}$ Similarly, in garnet SiAION an apatite and/or wollastonite, or $\mathrm{O}^{\prime}$ oxynitride phase would crystallize from the glass rich in oxygen while the AIN polytype solid-solution phases would crystallize from a glass rich in nitrogen. ${ }^{20}$ In addition to causing the crystallization of extraneous phases, deviations in composition might mean an increased residual glass content. That none of these phases are observed is important as the maximum reduction in glass phase content will occur when the glass is at the predetermined composition.

Cordierite exists in several modifications. ${ }^{23.24}$ In addition to the stable hexagonal $\alpha$ phase, a metastable quartz solid solution is
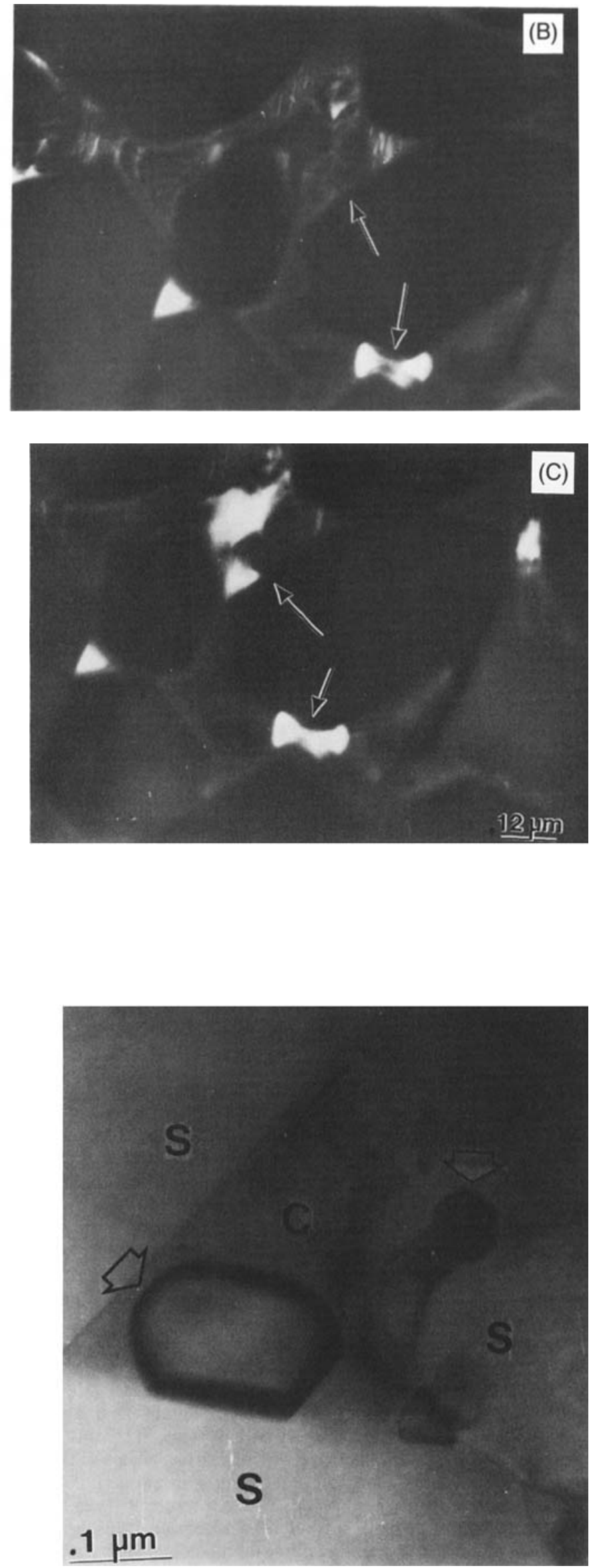

Fig. 4. Arrows point to the small faceted grains which are assumed to be silicon nitride that has precipitated with the cordierite. The SiAlON grains are labeled $S$ and the cordierite $C$. 

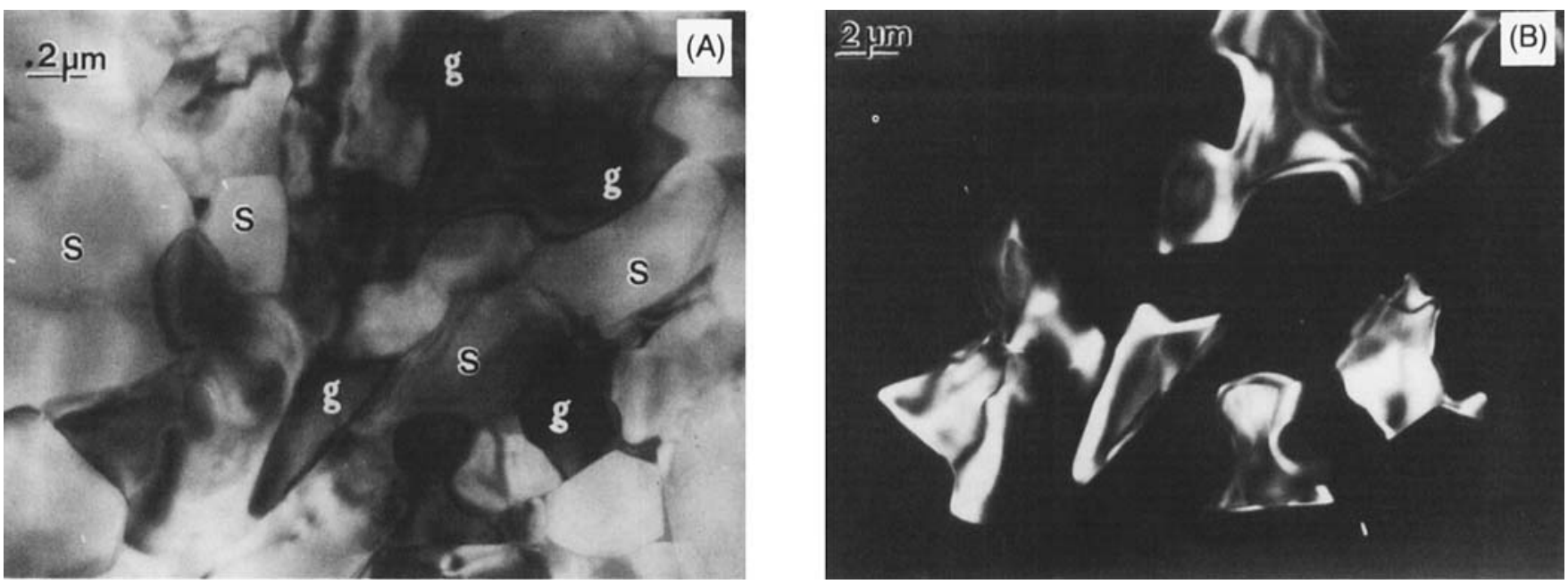

Fig. 5. A bright-field $(A)$-dark-field $(B)$ comparison illustrates the large size of crystallized garnet in SiAlON. Garnet $(G)$ can be identified in bright field by darker contrast because of its higher atomic number. The dark-field image is produced with a single spot from the garnet diffraction pattern. Bright area therefore represents a single grain.

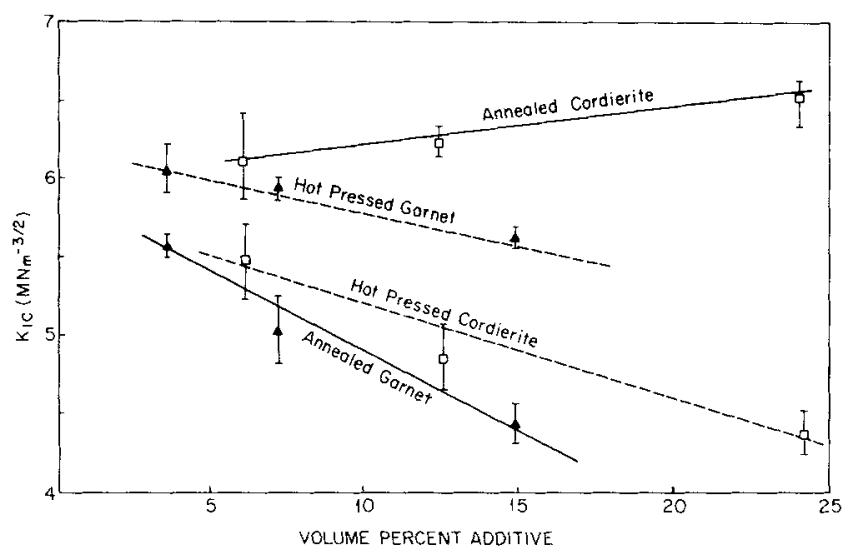

Fig. 6. Room-temperature fracture toughness is shown as a function of the volume fraction of second phase for cordierite and garnet SiAlON.

often observed. This metastable phase (sometimes referred to as $\mu$-cordierite) crystallizes from cordierite composition bulk glass annealed in the range of $700^{\circ}$ to $1000^{\circ} \mathrm{C}$ and transforms to stable cordierite when kinetic barriers do not exist. As described above, the samples discussed here were annealed at $1000^{\circ} \mathrm{C}$ to avoid this transformation in grain-boundary crystallization. However, it is interesting to note that although the metastable quartz derivative was observed on crystallization of bulk glasses with the grainboundary-phase composition (nitrogen-containing cordierite), ${ }^{25}$ it was never seen here as a grain-boundary-phase crystallization product even at temperatures as low as $850^{\circ} \mathrm{C} .^{26}$

The development of grain-boundary oxide morphology seen here is consistent with recent characterization of the associated secondary silicon nitride crystallization. ${ }^{17}$ The secondary silicon nitride was found to precipitate as small faceted grains among the crystallizing oxide in the cordierite SiAION system, in contrast to the garnet SiAlON system where it grows on existing silicon nitride grains. It is not clear whether these differences in nitride precipitation control the oxide morphology or are a result of it, as the oxide nucleation sites have not yet been identified. This is an important point because grain-boundary morphology manipulation by time/temperature variation will be limited. It is expected that control of oxide nucleation event frequency will lead to a more precisely controllable process.

The full impact of controlled grain-boundary crystallization will be felt when grain-boundary morphology as well as crystallization products can be controlled. The morphological differences observed on cordierite and garnet grain-boundary crystallization illustrate the combined effects of glass viscosity, oxide crystal structure, and crystallization mechanism. We expect the grainboundary cordierite glass to have a higher viscosity than the garnet. Using the conventional network model of glass structure, the average number of bridging oxygens per tetrahedron is much lower in the garnet composition glass (2.5) than in cordierite composition (3.5). ${ }^{27}$ Of course, both glasses will dissolve nitrogen, which has a large effect on viscosity, but earlier work indicates that both glasses can dissolve about the same amount of nitrogen and the effects of properties are of a similar magnitude. ${ }^{28,29}$ That the glasses retain their relative position with respect to viscosity is verified by sintering and grain growth studies in these systems. ${ }^{30}$

The observed differences in room-temperature indentation fracture toughness between the crystallized cordierite and garnet SiAlON may be related to differences in second-phase morphology. It may be pertinent to note, however, that the coefficient of thermal expansion for cordierite is about the same as that of silicon while garnet has a much higher thermal expansion coefficient. The larger residual stresses expected in the garnet SiAlON may produce regions of concentrated tension which could interact with the crack, causing the observed decrease in toughness. On the basis of experimental observations made here, it was not possible to distinguish between the contribution of morphology and residual stresses to the mechanical properties.

The potential of systematic controlled grain-boundary-phase crystallization is demonstrated in the "completeness" of crystallization and associated improvements in high-temperature properties for both the cordierite SiAlON and garnet SiAlON. Although a very fine amorphous layer is predicted to be stable at the grain boundaries of many ceramics, ${ }^{22,31}$ long-range atomic interactions are expected. These interactions could alter creep characteristics, as demonstrated by the degree of high-temperature deformation improvement illustrated here, to the point that effectively "complete" crystallization is realized. Application of this approach is by no means limited to the systems discussed here. With equilibrium phase relations or behavior diagrams of the appropriate systems and characterization of reactions which occur during processing, one should be able to predetermine crystallization products in any number of ceramic composite systems.

\section{Conclusions}

Controlled grain-boundary crystallization of amorphous phases 

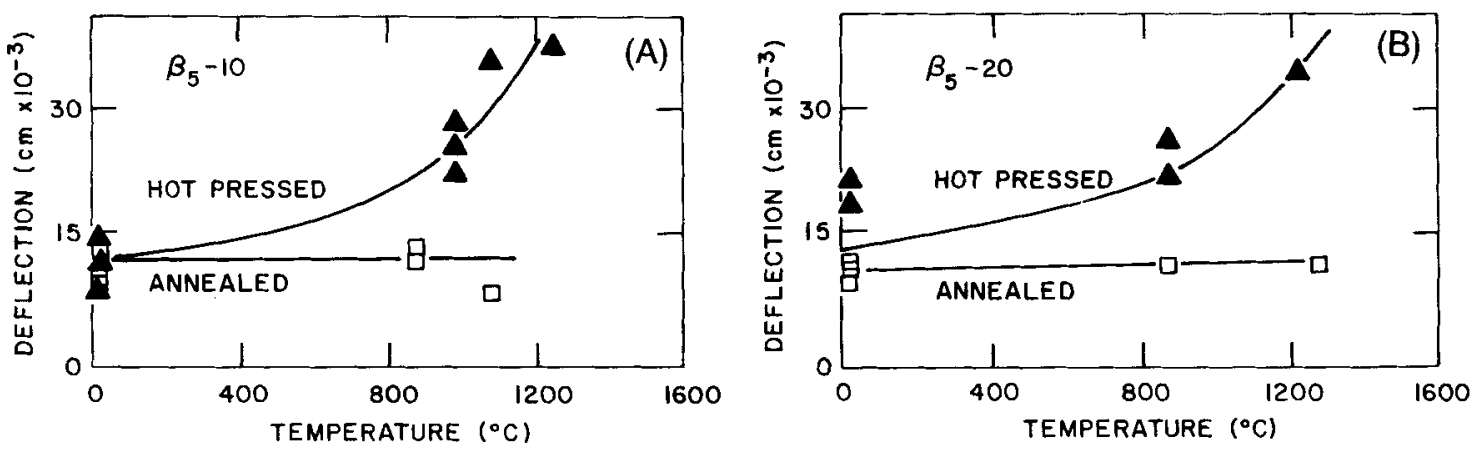

Fig. 7. Total deflection at failure in a four-point-bend test is shown as a function of temperature for cordierite SiAlON containing 10 and $20 \mathrm{wt} \%$ additive.

in SiAlON has been demonstrated in two systems. The annealed samples of both systems exhibited much less deformation in a high-temperature bend test than did the samples with glassy grain boundaries, indicating an improvement in creep resistance. Roomtemperature fracture toughness increased over that of glass containing SiAlON when cordierite crystallized but decreased when garnet crystallized. Although thermal expansion mismatch may affect room-temperature properties, dramatic differences in grainboundary morphology have been illustrated which may have an overriding influence on toughness. The cordierite SiAlON produced a fine polycrystalline microstructure whereas the garnet SiAlON produced a large interconnected structure. The development of grain-boundary morphology is discussed in terms of glass-phase viscosity during crystallization and nucleation mechanisms. Further work is necessary to characterize oxide crystallization mechanisms but the method of controlled grain-boundary crystallization presented here will allow precise manipulation of parameters important to such investigations.

Acknowledgments: The authors are especially grateful to D. R. Clarke, G Onoda. and R.F. Cook for making valuable suggestions regarding the manuscript.

\section{References}

${ }^{\prime}$ G. E. Gazza, R. N. Katz, and H. Knoch, "Factors Influencing the Quality of Fully Dense Silicon Nitride"; pp. 335-45 in Ceramics for High Performance Applications III. Edited by E. M. Lenoe, R. N. Katz, and J. J. Burke. Plenum Press. New York, 1984

${ }^{2}$ M. H. Lewis and R. J. Lumby, "Nitrogen Ceramics: Liquid Phase Sintering," Powder Metall., 26, 73-81 (1983).

${ }^{3}$ D. D. Messier. "The Alpha/Beta Silicon Nitride Phase Transformation," AMMRC Rept. No. AMMRC-TR-77-15, May 1977.

${ }^{4}$ L. J. Gauckler and G. Petzow, "Representation of Multi-Component Silicon Nitride Systems"; pp, 41-62 in Nitrogen Ceramics. Edited by F. L. Riley. Noordhoff The Netherlands, 1977.

${ }^{5} \mathrm{~F}$. F. Lange, "Phase Relations in the System $\mathrm{Si}_{3} \mathrm{~N}_{4}-\mathrm{SiO}_{2}-\mathrm{MgO}$ and Their Interrelation with Strength and Oxidation," J. Am. Ceram. Soc., 61 [1-2] 53-56 (1978)

"K. H. Jack, "Crystal Chemistry of SiAlONs and Related Nitrogen Ceramics": pp. 109-28 in Nitrogen Ceramics. Edited by F.L. Riley. Noordhoff, The Netherlands, 1977.

${ }^{7}$ H. F. Priest, G. G. Priest, and G. E. Gazza, "Sintering of Silicon Nitride Under High Nitrogen Pressure," J. Am. Ceram. Soc., 60 [1-2] 81 (1977).

${ }_{8}^{8}$. Prochazka and W. A. Rocco, "High Pressure Hot Pressing of Silicon Nitride Powders"; in Nitrogen Ceramics. Edited by F. L. Riley. Noordhoff, The Netherlands, 1981.
${ }^{9}$ D. R. Clarke, F. F. Lange, and G. D. Schnittgrund, "Strengthening of Sintered Silicon Nitride by Post-Fabrication Heat Treatment," J. Am. Ceram. Soc. 65 [4 C-51-C-52 (1982).

${ }^{10}$ D. R. Clarke, "Compositional Modifications of Hot-Pressed Silicon Nitride by High-Temperature Electrolysis," J Am. Ceram. Soc. 67 [7] 455-59 (1984).

IIA.Rae, D. P. Thompson, N. J. Pipen, and K. H. Jack; Specjal Ceramics 6. Edited by P. Popper. British Ceramic Research Association, Stoke-on-Trent, England, 1976. ${ }^{12}$ A. Tsuge, K. Nishida, and M. Komatsu, "Effect of the Grain-Boundary Glass Phase on the High-Temperature Strength of Hot-Pressed Silicon Nitride Containing Yttria," J. Am. Ceram. Soc., 58 [7-8] 323-26 (1975)

${ }^{13}$ S. Wild, P. Grieveson, K. H. Jack, and M. Latimer; p. 377 in Special Ceramics 5. Edited by P. Popper. British Ceramic Research Association, Stoke-onTrent, England, 1972

${ }^{14} \mathrm{H}$. Honke and T. Y. Tien, "Solid-Liquid Reactions in Part of the System $\mathrm{Si}, \mathrm{Al}, \mathrm{Y} / \mathrm{N}, \mathrm{O}^{\prime}$; pp. 101-10 in Progress in Nitrogen Ceramics. Edited by F. L. Riley. Martinus Nijhoff. The Hague, The Netherlands, 1983.

${ }^{15}$ M. H. Lewis, A. R. Bhatti, R.J. Lumby, and B. North, "Microstructure of Sintered Si-Al-O-N Ceramics,"J, Mater. Sci., 15, 103-13 (1980)

${ }^{16}$ F. F. Lange, S. C. Signhal, and R. C. Kuznicki, "Phase Relations and Stability Studies in $\mathrm{Si}_{3} \mathrm{~N}_{4}-\mathrm{SiO}_{2}-\mathrm{Y}_{2} \mathrm{O}_{3}$ Pseudoternary Systems," J. Am. Ceram. Soc, $60[5-6]$ $249-52(1977)$

${ }^{17}$ D. A. Bonnell, M. Ruhle, and T. Y. Tien, "Redistribution of Aluminum lons During Processing of Sialon Ceramics," J. Am. Ceram. Soc., 69 [8] 623-27 (1986) ${ }_{18}^{18}$ I.K. Naik and T. Y. Tien, "Subsolidus Relations in Part of the System Si,Al,Y/N,O,"J.Am. Ceram. Soc., $62[11-12] 642-43$ (1979).

${ }^{19}$ K. H. Jack. "The Significance of Structure and Phase Equilibria in the Devel opment of Silicon Nitride Ceramics"; pp. 125-42 in Science of Ceramics 11. Sherwin Rivers, Ltd. Stoke-on-Trent. England, 1981.

${ }^{20}$ G. R. Anstis, P. Chantikul, B. R. Lawn, and D. B. Marshall, "A Critical Evaluation of Indentation Techniques for Measuring Fracture Toughness: I. Direct Crack Measurement," J. Am. Ceram. Soc., 64 [9] 533-38 (1981)

${ }^{2 i}$ G. D. Quinn, "Guide to Constructing a Simple $1500^{\circ} \mathrm{C}$ Test Furnace," AMMRC Rept. No. AMMRC-TN-77-4, 1977

${ }^{22}$ D. R. Clarke, "Grain Boundaries in Polyphase Ceramics," J. Phys. (Orsay, Fr.), 46. C4-51-59 (1985)

${ }^{23}$ W. Schreyer and J. F. Schairer, "Compositions and Structural States of Anhydrous Mg.Cordierites - A Reinvestigation of the Central Part of the System MgO$\mathrm{Al}_{2} \mathrm{O}_{3}-\mathrm{SiO}_{2}, " J$. Petrol., 2, 324-93 (1961).

${ }_{24}$ W. Schreyer and J.F. Schairer, "Metastable Solid Solution with Quartz Type Structures on the Join $\mathrm{SiO}_{2}-\mathrm{MgAl}_{2} \mathrm{O}_{4}$," Z. Kristallogr.. 116, 60-81 (1961)

${ }^{25} \mathrm{~T}$. Hayashi and T. Y. Tien; unpublished work.

${ }^{26} \mathrm{D}$. Bonnell. "Determination of Crystallization Mechanisms and Correlation to Grain Boundary Morphology Mechanical Properties in SiAlON Ceramics": Ph.D. Dissertation. The University of Michigan, Ann Arbor, MI

${ }_{27} \mathrm{~S}$. H. Risbud, "Analysis of Bulk Amorphus Oxynitride Structures Using the Net${ }^{2} \mathrm{~S}$. H. Risbud, "Analysis of Bulk Amorphus Oxynitride Structures Using
work Theory of Glasses," Phys. Chem. Glasses, II, 22, 168-79 (1981).

${ }_{28} \mathrm{~J}$. Homeney and D. L. McGarry, "Preparation and Mechanical Properties of Mg-Al-Si-O-N Glasses," J. Am. Ceram. Soc., 67 [11] C-225-C-227 (1984).

${ }^{29} \mathrm{~S}$. Hampshire, R. Drew, and K. H. Jack, "Viscosities, Glass Transition Temperatures, and Microhardness of Y-Si-Al-O-N Glasses," J. Am. Ceram. Soc., 67 [3] C-46-C-47 (1984)

${ }^{30}$ T. Y. Tien, "Effect of Microstructure on Mechanical Properties of Silicon Nitride Ceramics," U.S. DOE Rept. No. DE-FG02-84-ER45069.

${ }^{31}$ A. Thorel, J. Y. Laval, D. Broussaud, D. de Sagey, and G. Schiffmacher, "Grain Boundary Structure of SiAloNs for Thermochemical Applications," Grain Boundary Structure and Related Phenomenon Supplement to Trans. Jpn. Inst. Met., 819-26 (1986). 